\section{Breezing into town}

\section{The world's highest} urban wind farm could be a flagship project for renewable energy, if New York City planners get their way. Are city dwellers ready for wind power? Jonathan Knight investigates.

E veryone remembers where they were on 11 September 2001. Building engineer Sinisa Stankovic was at the Rutherford Appleton lab near Oxford, UK, for a day-long workshop on renewable energy. He and his colleagues had just presented results from a two-year study on how to integrate wind turbines into city buildings, when news of the terrorist attacks came in.

Now, in a strange twist for Stankovic, the planned redevelopment of Ground Zero in lower Manhattan might give a boost to urban wind power. The site's signature structure, the Freedom Tower, is scheduled for a ceremonial groundbreaking on 4 July, American Independence Day, and is also set to host the world's tallest wind farm.

If built as planned, the tower would be the world's most visible symbol of renewable energy, with as many as 30 spinning wind turbines in its upper storeys, providing a fifth of the building's power. "The Ground Zero turbines will be high-profile, and that might spur a lot more interest in wind," says Stankovic, who is a founder of the London-based ecological design consultancy BDSP Partnership.

So is this the shape of things to come? Many wind-power enthusiasts say that rooftop generation will play a role in the future, as fossil-fuel supplies dwindle and customers seek greater independence from the creaking electrical power grid. Others doubt whether urban wind power will have much success, and some are even sceptical that the Freedom Tower turbines will be built.

Today, most wind generation occurs at wind farms in remote rural areas or offshore, where the wind blows on average three times stronger than in cities. These giant turbines, with rotating blades 20-60 metres long, can each generate up to 5 megawatts, enough to power a large office building.

The largest turbines in cities are also free-

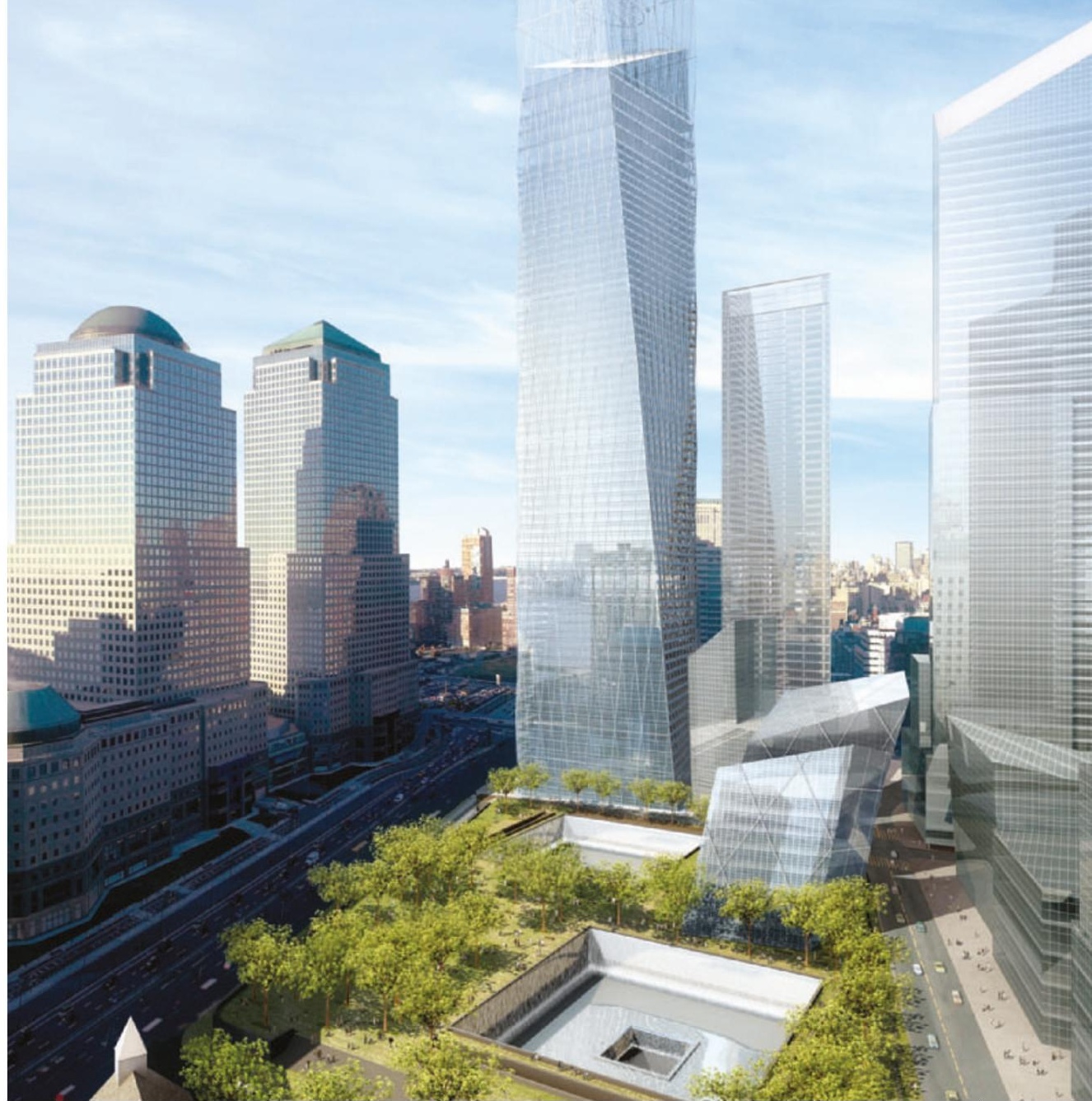

standing units. Toronto boasts a 30-storey lakeside windmill that can power up to 250 houses when spinning. Unlike rural wind farms that are often opposed by residents on aesthetic grounds, Toronto's turbine has the enthusiastic support of the local community, who raised $50 \%$ of the installation costs.

\section{Winds of change}

Yet rooftop windmills are rarely seen, despite the fact that wind turbines are cheaper to install and run than solar panels. According to wind-power experts, building owners have concerns that turbines might be too noisy or heavy. Others consider the huge spinning blades unsightly or even dangerous.

Enthusiasts for urban wind power believe these problems can be overcome. "We think wind power fits better into a man-made environment than a pristine one,"Stankovic says.
With limited space for rural wind farms, Europe has taken the lead in research into urban wind power. The European Union expects member nations to get some $12 \%$ of their energy from renewable sources by 2010 , and Britain is seeking to derive at least $20 \%$ from renewables by 2020 . Achieving these goals will require less centralized production, with consumers using solar panels or wind turbines to generate some of their own power.

In 1998, Stankovic helped to coordinate a project funded by the European Commission to explore ways of incorporating wind power into cities. Project WEB (Wind Energy for the Built Environment) concluded that buildings designed or retrofitted with wind turbines need to get at least $20 \%$ of their electricity from wind to justify the installation cost. To help achieve this, the shape of the building should be designed to 
kilometres per hour, so an escaping blade fragment could do considerable damage.

Urban-wind proponents say that such fears are unfounded. Modern turbines have safety features including speed control and blades that turn edge-on into the wind during storms. Perhaps the biggest challenge for building-mounted turbines is noise.

Any slight imbalance in the blades is amplified by centrifugal forces, causing the turbine to shake when rotating. "No rotating machinery is perfectly balanced," says Clint 'Jito' Coleman, president of Northern Power Systems in Waitsfield, Vermont, and a 30-year veteran of the wind-power business. "Any imbalance shows up once per revolution, and there is nothing you can do about it."

The noise produced can vary from a regular thump to a low rumble. Should the turbine speed match the harmonic resonance frequency of the surrounding structure, such as a supporting beam, then the building itself can also vibrate, amplifying the sound.

"They can turn your roof into a big loudspeaker," says Mike Bergey, who runs Bergey Windpower in Norman, Oklahoma, one of the oldest wind-power companies in the United States.

If the turbine is part of the original design, as in the Freedom Tower, it should be possible to dampen vibrations by constructing heavy support structures, Bergey says. But that gets expensive. When the architects began looking for a wind-power company to design their turbines earlier this year, both Bergey and Coleman decided not to bid, believing that the cost would be prohibitive. "I'm sceptical that there will ever be turbines up there," Bergey says.

A spokeswoman for Skidmore, Owings \& Merrill declined to answer Nature's questions about the Freedom Tower turbines or to say whether an engineering firm had been chosen to build them. But one windpower company that is bidding on the Freedom Tower project says that it has the solution to vibrations: vertical-axis turbines. Unlike traditional windmills with their propeller-like blades, vertical turbines have curved blades that are attached at both ends to a vertical shaft. They spin whatever the wind direction.

Gary Westerholm, president of McKenzie Bay International in Brighton, Michigan, says that vertical turbines produce less vibration at a given rotation speed because the blades do not stick out so far and so exert less pull.

To reduce the vibrations still further, Westerholm proposes installing 30 small, 100 kilowatt, turbines in the Freedom Tower, rather than fewer large ones. The turbines also automatically change speed if they approach resonance frequencies of any components.

Despite these advantages, vertical turbines have not been commercially successful. The few firms pursuing them in the 1970s and 1980 s ran into financial problems, says Robert Thresher, director of the National Wind Technology Center in Golden, Colorado. "It was basically bad luck," he says. Even today, there are few installations of vertical turbines.

\section{Vertical challenge}

Most low-rise city buildings don't have room for 30 turbines, whatever their size, and suffer from weak and unreliable winds. So a pilot project in Scotland is exploring ways to make small turbines more attractive to architects by combining them with other technologies that reduce a building's power needs.

Designed by Charles Rennie Mackintosh, Scotland's best known architect, Glasgow's 1895 Lighthouse Building is a national treasure. When it was refurbished in 1999, engineers at the Energy Systems Research Unit (ESRU) of the University of Strathclyde were consulted about adding wind and solar power.

The redesign added openings just below the roofline to channel air up through ducts, across turbine blades and out onto the roof. Ducts offer several advantages. By channelling the wind, they reduce air turbulence before the air meets the rotor. They also allow the turbines to be hidden away, and prevent broken blades from escaping and doing damage, says ESRU director Joe Clarke.

The Lighthouse Building's other efficiency features include windows that keep heat in during winter and out in the summer, motion sensors that ensure only occupied rooms are heated, and lights that dim if there is enough daylight available. Combined, these measures make the building $70 \%$ more efficient than the UK best-practice standards require. As a result, the turbines can produce up to a third of the building's annual power consumption ${ }^{2}$.

Although no projects as ambitious as the Freedom Tower have yet been built, the number of small windmills is on the rise. In the Netherlands, dozens of them spin on rooftops in The Hague and Amsterdam. And from this May, the Scottish government is funding a trial of small turbines on the roofs of primary schools in Fife.

Tourists visiting the viewing platform of the Freedom Tower won't fail to notice its patriotic symbolism. The finished tower will rise to 1,776 feet (545 metres) — a reference to the year of American independence and its capping spire is supposed to mirror the Statue of Liberty's upraised arm. But will visitors be surprised to see windmills among the skyscrapers? By 2015, perhaps not.

Jonathan Knight writes for Nature from San Francisco.

1. Campbell, N. et al. in Proc. European Wind Energy Conf. \& Exhibition (EWEA, Brussels, 2001); http://www.bdsp.com/web

2. Clarke, J. A. et al. in Proc. 16th European Photovoltaic Solar Energy Conf. (James \& James, London, 2000) $\mathrm{ftp}: / / \mathrm{ftp}$.strath.ac.uk/Esru_public/documents/LH-PV.pdf 